Review Article

\title{
Morphometric Analysis of Biasterion Length and Cranial Vault Weight of Nigerian Skulls
}

\author{
Chinna Nneka Orish ${ }^{1, *}$, Valentine Chidozie Amasiatu ${ }^{2}$ \\ ${ }^{1}$ Department of Anatomy, Faculty of Basic Medical Science, University of Port-Harcourt, Port-Harcourt, Nigeria \\ ${ }^{2}$ Department of Anatomy, Gregory University Uturu, Uturu, Nigeria
}

Email address:

chinnaorish@yahoo.com (C. N. Orish)

${ }^{*}$ Corresponding author

\section{To cite this article:}

Chinna Nneka Orish, Valentine Chidozie Amasiatu. Morphometric Analysis of Biasterion Length and Cranial Vault Weight of Nigerian Skulls. International Journal of Biomedical Science and Engineering. Vol. 8, No. 2, 2020, pp. 19-21. doi: 10.11648/j.ijbse.20200802.13

Received: May 1, 2020; Accepted: June 3, 2020; Published: June 28, 2020

\begin{abstract}
Anthropometry involves the systematic measurement of the physical properties of the human body, primarily dimensional descriptors of body size and shape. It plays an important role in industrial design, clothing, ergonomics and architecture. Skull is important in this regard as it resists adverse environmental conditions over time. The present study aims to determine the anthropometric dimensions of biasterion length and cranial vault weight of Nigerian skulls. One hundred adult dry skulls, (82 males, and 18 females) free from damage and deformities collected from eleven Departments of Anatomy in Nigerian Universities were used. Tape and weighing scale were used to measure biasterion length and weight of cranial vault. Data was analyzed with Graph Pad Prism 5.03. The mean \pm SEM, maximum, minimum and sexual dimorphism ratio were computed. The mean of biasterion length $(\mathrm{mm})$ of male and female were $127.0 \pm 0.90$ and $123.0 \pm 1.56 \mathrm{~mm}$ respectively while the weight of cranial vault for male and female were $330 \pm 6.08$ and $308 \pm 7.84$ respectively. The result of this study will be of importance in providing new perspectives on human osteology and in sex determination in forensic anthropology.
\end{abstract}

Keywords: Skull, Anthropometry, Crania Vault, Biasterion Length, Forensic Science

\section{Introduction}

Anthropometry is an important part of physical/biological anthropology that measures different parts of the human body. As an invaluable tool of physical anthropology, it has been used for identification, for the purposes of understanding human physical variation, in paleoanthropology and in various attempts to correlate physical with racial and psychological traits. It plays an important role in industrial design, clothing design, ergonomics and architecture where statistical data about the distribution of body dimensions in the population are used to optimize products. Changes in lifestyles, nutrition, and ethnic composition of populations lead to changes in the distribution of body dimensions and require regular updating of anthropometric data collections.

Craniometry is the measurement of cranial features to classify people according to race, criminal temperament, intelligence. Forensic anthropologists believe that by taking some 90 measurements of a skull they can correctly assign its owner's continent of origin - broadly speaking, its race, though many anthropologists prefer not to use that term - with 80 percent accuracy [1]. Skull is made up various parts which include frontal, temporal, occipital and parietal. Asterion are situated on the temporal region. The temporal bone is highly resistant to physical damage; thus, it is commonly found as remainder in skeletons that are very old; of this, the petrous portion has been described as important for sex determination. Kalmey Paiva \& Segre [2] introduced mastoid triangular area calculated between the points porion, mastoidale, and asterion, as easy technique for sex determination starting from the temporal bone. Other Caucasian researchers [3-8] had also worked on biasterion length, however there is paucity of information in Nigeria. This study has characterized anthropometric features of biasterion length and cranial vault weight of Nigerians. 


\section{Materials and Methods}

A total of 100 adult dry skulls (82 males, 18 females), free from damage and deformity fully ossified collected from Departments of Anatomy in Nigerian Universities were used for this study. Tape, marker and weighing scale were used to measure Biasterion length and weigh cranial vault.

1: Biasterion Length. It measures the straight distance between the two asterion. The skull was placed with Norma occipitalis facing the observer

Asterion: Point where the temporal, parietal and occipital bones meet.

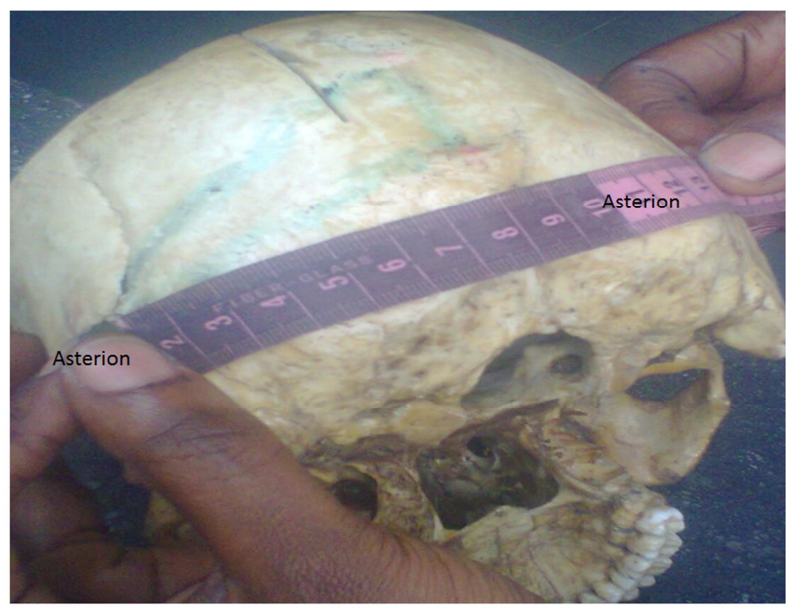

Figure 1. Biasterion length.

Data was analyzed with Graph Pad Prism 5.03. The mean, standard error of mean, maximum, minimum, and sexual dimorphism ratio were computed. Student T-test was used to compare male-female measurements.

\section{Results}

Table 1. Effect of sex on biasterion and cranial vault weight.

\begin{tabular}{llllll}
\hline Parameters & Sex & Mean \pm SEM & Maximum & Minimum & $\begin{array}{l}\text { Significant } \\
\text { level }\end{array}$ \\
\hline Cranial vault & M & $330 \pm 6.08$ & 500 & 280 & $\mathrm{p}<0.05^{*}$ \\
weight & F & $308 \pm 7.64^{*}$ & 400 & 280 & \\
Biasterion & M & $127.0 \pm 0.90$ & 157.0 & 110.0 & $\mathrm{p}<0.05^{*}$ \\
length & F & $122.27 \pm 0.80$ & 136.0 & 136.0 & \\
\hline
\end{tabular}

Table 2. Sexual dimorphism ratio.

\begin{tabular}{llll}
\hline Parameters & $\begin{array}{l}\text { Male } \\
\text { (mean) }\end{array}$ & $\begin{array}{l}\text { Female } \\
\text { (mean) }\end{array}$ & $\begin{array}{l}\text { Sexual dimorphism } \\
\text { ratio (Mean M/Mean F) }\end{array}$ \\
\hline Biasterion length & 127.0 & 123.0 & 1.03 \\
Cranial Vault weight & 330 & 308 & 1.07 \\
\hline
\end{tabular}

The effect of sex on biasterion length and weight of cranial vault is shown on Table 1 . The male cranial parameters were higher than female parameter. Table 2 shows sexual dimorphism ratio of Biasterion length and weight of cranial vault parameters. The male/female ratios for the mean measurements were greater than unity, indicating that the male crania were larger in the male dimensions than female crania.

\section{Discussion}

Craniometry which is defined as measurement of skull is an invaluable tool to forensic expert with respect to race determination and surgeons in face of surgical intervention. The comparison of the mean values of both cranial vault weight and biasterion length of Nigerian population with Caucasians showed some variations which can attributed to a complex interaction between genetic and environmental factors, as well as racial variations.

Deshmukh and Devershi. [3] reported biasterion length to be $101 \pm 4.53$ and $98 \pm 3.75 \mathrm{~mm}$ for male and female respectively and was found to be significant by univariate analysis with $p<0.05$. Steyna and Iscan [9] in their work titled sexual dimorphism in the crania and mandibles of South African whites using 43 males and 46 females found biasterion length to be $113.7 \pm 4.99$ and $109.7 \pm 4.91 \mathrm{~mm}$ respectively was also statistically significant at $\mathrm{p}<0.05$. In a Chinese study using 30 male and 50 female skulls, the biasterion length of males was significantly higher than females [10]. The present study which has reported male and female biasterion length to be $127.0 \pm 0.90$ and $123.0 \pm 1.56 \mathrm{~mm}$ respectively is however higher than the biasterion lengths reported by Deshmukh and Devershi, Steyna and Iscan [3, 9]. In all these studies the male parameter remained higher than female.

Some other studies on cranial parameters [3, 11-13] study on India population reported cranial weight to be higher in male than female which coincides well with the present study.

Ahmed et al., [14-15] reported that sexual dimorphism ratio (male/female ratios) for the mean measurements were greater than unity, indicating that the male crania were larger in all linear dimensions than female crania. This correlates well with the present study which reported that sexual dimorphism ratio for the mean measurements were greater than unity too.

\section{Conclusion}

The morphometric analysis of biasterion length and cranial vault weight of Nigerian skulls has shown high level of sexual dimorphism. Knowledge of anthropometric dimensions biasterion lengths and cranial vault weight can be a vital tool to the forensic experts, anthropologist and surgeons.

\section{References}

[1] Wade, Nicholas. 2002. "A New Look at Old Data May Discredit a Theory on Race," New York Times, October 8.

[2] Saavedra de Paiva LA, Segre M. Sexing the human skulls through the mastoid process. Rev Hosp Clin Fac Med Sao Paulo. 2003; 58 (1): 15-20.

[3] Deshmukh AG \& Devershi DB Comparison of Cranial Sex Determination by Univariate and Multivariate Analysis, 1J. Anat. Soc. India.. 2006; 55 (2) 48-51. 
[4] Keen JA. A study of the differences between male and female skulls. Am J Phys Anthropol. 1950; 8 (1): 65-79.

[5] Giles E \& Elliot G. Sex determination by discriminant function analysis of crania. American Journal of physical anthropology; 1963; 21: 53-56.

[6] Sumati, Patnaik VVG, Phatak A, Determination of sex from mastoid process by discriminant function analysis. J Anat Soc India, 2010; 59 (2) 222-228.

[7] Kranioti, E. F., İşcan, M. Y., \& Michalodimitrakis, M. (2008). Craniometric analysis of the modern Cretan population. Forensic Science International, 180 (2-3), 110-e1.

[8] Das Gupta A, Banerjee A, Kumar A, Rao SR and Jose J, Discriminant Function Analysis of Mastoid Measurements in Sex Determination. J Life Sci, 2012; 4 (1): 1-5.

[9] Maryna S., Iscan MY. Sexual dimorphism in the crania and mandibles of South African whites. Forensic Science international; 1998; 98: 9-22.

[10] Song, H. W., Qing, L. Z., \& Tao, J. J. (1992). Sex diagnosis of Chinese skulls using multiple stepwise discriminant function analysis. Forensic science international, 54 (2), 135-140.
[11] Ramamoorthy, B., Pai, M. M., Prabhu, L. V., Muralimanju, B V., \& Rai, R. (2016). Assessment of craniometric traits in South Indian dry skulls for sex determination. Journal of forensic and legal medicine, 37, 8-14.

[12] Orish, C. N., Didia, B. C., \& Fawehinmi, H. B. Sex Determination Using Inion-Opistocranium-Asterion (IOA) Triangle in Nigerians' Skulls. Anatomy Research International, 2014: 747239. doi: 10.1155/2014/747239. Epub 2014 May 18.

[13] Orish CN, Ibeachu PC, Didia BC, Craniometric analysis of Nigerian population. Anatomical Sciences Journal. Iran, 2014: 11 (2); 93-97.

[14] Ahmed AA, Mohammed HA, Hassan MA, Sex determination from cranial measurements in recent northern Sudanese. Khartoum Medical Journal. 2011; 4 (1), pp. 539547.

[15] Mohammed Madadin, Hind S. Al Saif, Afnan Al Muhanna, Abid H. Gullenpet, K. R. Nagesh, Magdy A. Kharoshah, Bander Al Dhafery. "Morphometric evaluation of the foramen magnum for sex determination: A study from Saudi Arabia." Journal of forensic and legal medicine 46 (2017): 66-71. 